\title{
DESJUDICIALIZAÇÃO DA SAÚDE , DIÁLOGOS INTERINSTITUCIONAIS E PARTICIPAÇÃO SOCIAL: EM BUSCA DE ALTERNATIVAS PARA O SISTEMA
}

\author{
CLARA MACHADO ${ }^{1}$ \\ SANDRA REGINA MARTINI ${ }^{2}$
}

RESUMO: A judicialização da saúde enquanto estratégia para a garantia do direito à saúde tem-se mostrado cada vez mais insuficiente e obsoleta, sendo necessário buscar novas soluções e alternativas para a manutenção do sistema único de saúde. O monitoramento produzido pelo eixo temático "Acompanhamento das Decisões Judiciais Relativas à Saúde", do Observatório de Análise Política em Saúde (OAPS) em 2017 aponta que os gastos federais com processos judiciais na área da saúde continuam crescentes, fato que coloca em jogo a manutenção do sistema único de saúde e demonstra que a judicialização não resolve o problema. Diante deste quadro, este artigo propõe repensar o fenômeno da judicialização a partir do princípio constitucional da fraternidade ao potencializar o diálogo insterinstitucional e fomentar o dever de participação social na definição e estruturação de políticas públicas adequadas à realidade social. Defende-se, desta forma, a criação de instrumentos de desjudicialização da saúde, como forma de garantir a efetividade do direito à saúde. Para tanto, serão utilizadas as técnicas típicas da metodologia de pesquisa indutiva e descritiva com o auxílio dos instrumentos de pesquisa típicas de uma pesquisa descritiva, quais sejam, o levantamento, a revisão e o fichamento bibliográfico documental/legal.

Palavras-Chave: Desjudicialização da saúde; Diálogos Interinstitucionais; Participação social; Fraternidade.

\footnotetext{
${ }^{1}$ Doutora em Direito pela Universidade Federal da Bahia. Professora do Mestrado em Direitos Humanos da UNIT. E-mail: claracardosomachado@gmail.com.

2 Doutora em Evoluzione dei Sistemi Giuridici e Nuovi Diritti pela Università Degli Studi di Lecce (2001), Pós-doutorado em Direito (Roma Tre, 2006) e Pós-doutorado em Políticas Públicas (Universidade de Salerno, 2010). Professora do Centro Universitário Ritter dos Reis (Uniritter) e professora-visitante no programa de pós-graduação em Direito da UFRGS.
} 


\title{
DESJUDICIALIZAÇÃO DA SAÚDE , DIÁLOGOS \\ INTERINSTITUCIONAIS E PARTICIPAÇÃO SOCIAL
}

\section{HEALTH DISJUDICIALIZATION, INTERINSTITUTIONAL DIALOGUES, SOCIAL PARTICIPATION: IN SEARCH OF ALTERNATIVES FOR THE SYSTEM}

\begin{abstract}
Health judicialization as a strategy to guarantee the right to health has become increasingly insufficient and obsolete, and it is necessary to seek new solutions and alternatives for the maintenance of the Unified Health System. The monitoring produced by the thematic axis "Monitoring of Judgments Relating to Health", of the Observatory of Political Analysis in Health in 2017, points out that federal expenditures with health judicial processes continue to increase, a fact that puts at stake the maintenance of the Unified Health System and demonstrates that judicialization does not solve the problem. In view of this situation, this article proposes to rethink the phenomenon of judicialization based on the constitutional principle of fraternity by enhancing interinstitutional dialogue and to foment the duty of social participation in the definition and structuring of public policies appropriate to social reality. It is defended, in this way, the creation of instruments of disjudicialization of health, as a way to guarantee the effectiveness of the right to health. For this, it will be used the typical techniques of inductive and descriptive research methodology with the aid of the typical research instruments of a descriptive research, that is, the survey, the revision and the bibliographic documentary/legal file.
\end{abstract}

KEYWORDS: Health disjudicialization; Interinstitutional Dialogues; Social participation; Fraternity. 


\section{REVISTA ESTUDOS INSTITUCIONAIS}

\section{INTRODUÇÃO}

Apesar dos inúmeros estudos desenvolvidos sobre judicialização da saúde, o tema segue carente e continua a instigar reflexões e a demandar alternativas concretas para a efetivação do direito social à saúde e controlar o crescimento desregrado das demandas judiciais.

Estudo do Observatório de Análise de Políticas em Saúde (OAPS), produzido pelo eixo temático "Acompanhamento das Decisões Judiciais Relativas à Saúde" destacou o aumento de processos judiciais relacionados à área de saúde ${ }^{3}$ bem com os gastos da União com ações envolvendo prestações de saúde em que se verificou um aumento de $1300 \%$ em sete anos, considerando o lapso temporal de 2008 para 2015 (OAPS, 2017). Na auditoria operacional feita pelo Tribunal de Contas da União (TCU) entre 2015 e 2016 ficou demonstrado gastos crescentes, "que saltaram de R\$ 70 milhões em 2008 para R\$ 1 bilhão em 2015" (BRASIL, 2017, p. 03)

Sem dúvida, o direito à saúde é fruto de várias lutas sociais, e há um eterno questionamento se é possível atender todas as demandas da sociedade nessa temática. Um dos caminhos encontrados na década de noventa para a efetivação deste direito e garantia do comando constitucional foi a judicialização. Ocorre que o protagonismo desenfreado e excessivo do Judiciário tem ocasionado incertezas e contradições no sistema que exige um repensar de seu sentido e limites. Hoje, tem-se a clareza de que a judicialização da política não resolveu o problema da eficácia dos direitos sociais, em especial do direito à saúde, e instigou a necessidade de repensar o fenômeno, apresentando como alternativa à concretização do direito à saúde, a desjudicialização.

Este artigo pretende, com base os resultados provenientes das pesquisas desenvolvidas pelo Grupo de Pesquisa "Direitos Fundamentais, Novos Direitos e Evolução Social, na análise dos relatórios produzidos pelo Observatório de Análise Política em Saúde (OAPS) e pelo Departamento de Informática do SUS (DATASUS) demonstrar que a desjudicialização da saúde a partir do princípio jurídico da fraternidade pode ser uma alternativa à concretização do direito à saúde, através de instrumentos que viabilizem maior participação social e fomento de diálogos insterinstitucionais.

A hipótese da desjudicialização da saúde foi levantada a partir de dados constantes nos relatórios da OAPS produzidos em 2017 que constatam mecanismos para conter o avanço da judicialização e a

\footnotetext{
${ }^{3}$ Mais detalhes sobre os processos podem ser buscados no próprio relatório “Justiça em Números 2017 (BRASIL, 2017c).
} 


\section{DESJUDICIALIZAÇÃO DA SAÚDE , DIÁLOGOS INTERINSTITUCIONAIS E PARTICIPAÇÃO SOCIAL}

ampliação do debate, por meio de audiências públicas, cooperação entre entes na gestão dos impactos dos processos judiciais na área da saúde orientada pela Comissão Intergestores Tripartite (CIT), dentre outros (OAPS, 2017).

Partindo-se da hipótese da desjudicialização pretende-se demonstrar o aporte jurídico filosófico do fenômeno considerando o princípio da fraternidade enquanto fundamento necessário à concretização dos direitos de caráter coletivo, a exemplo da saúde. Assim, o artigo foi dividido em três partes.

Em um primeiro momento, apresenta-se a perspectiva da desjudicialização da política enquanto fenômeno necessário na contemporaneidade. Após, tecem-se algumas considerações sobre a fraternidade em um viés jurídico-constitucional. Ao final, com o intuito de conferir funcionalidade a teoria, discorre-se sobre a desjudicialização da saúde como alternativa a sua efetivação, a partir de instrumentos que fomentem a criação de uma estrutura dialógica apta a enxergar as necessidades públicas e construir as políticas públicas com a participação da sociedade.

Como metodologia aplicada à pesquisa, utilizou-se, inicialmente, do método de pesquisa denominado de indutivo, uma vez que entre as perspectivas de trabalho foram utilizadas: a identificação do processo de judicialização das políticas públicas, a abrangência do direito quando envolto na seara das políticas públicas, a observação do processo de construção conceitual do princípio jurídico da fraternidade e a sua aplicação na área do direito à saúde. Posteriormente, após o encontro da premissa geral, possibilitada pelo método anteriormente descrito, se utilizou o método descritivo, uma vez que o raciocínio parte de uma premissa geral e volta-se para uma situação particular descrita através da revisão bibliográfica e documental, qual seja, o de verificar instrumentos para desjudicialização da saúde.

Quanto aos procedimentos, pode-se dizer que na pesquisa em questão foram utilizadas as técnicas provenientes dos tipos de pesquisas bibliográfica e documental, visto que foram utilizadas as técnicas de revisão e fichamento bibliográfico em doutrinas e documentos especializados, a exemplo de relatório do Observatório de Análise Política em Saúde (OAPS), de modo a possibilitar a consecução dos objetivos anteriormente expostos. 


\section{REVISTA ESTUDOS INSTITUCIONAIS}

\section{II. (DES) JUDICIALIZAÇão DA POLÍTICA PÚBLICA DE SAÚDE}

Ao longo do processo evolutivo observamos que os sistemas sociais foram se diferenciado e se especializando. $\mathrm{O}$ sistema do direito ${ }^{4}$ passa a ser diferente da política, da religião, da educação e de todos os demais sistemas sociais, porém esta diferença não é distanciamento, mas é a possibilidade do direito contribuir com os demais sistemas sociais. $\mathrm{O}$ mesmo ocorre para qualquer outro sistema. A Teoria Geral dos Sistemas sociais, identifica que esta sociedade é uma rede ou uma malha de comunicação, onde cada sistema opera de modo fechado, mas é cognitivamente aberto. Os sistemas parciais operam através da comunicação especializada, o que permite que cada sistema tenha uma função específica que o diferencia e ao mesmo tempo aproxima de outros sistemas sociais. Por exemplo, a função do sistema da política é tomar decisões coletivamente vinculantes, enquanto que a função do sistema do direito é manter estável as expectativas jurídicas.

A crescente importância do Poder Judiciário na mediação das relações sociais deu guarida ao fenômeno da judicialização da política. Judicialização significa que questões de grande repercussão social estão sendo decididas pelo Poder Judiciário e não pelas instâncias políticas tradicionais (Poder Legislativo e Poder Executivo).

O fenômeno comporta múltiplas causas. Voltando os olhares para o ordenamento jurídico pátrio, a força normativa da Constituição de 1988 seguida da constitucionalização abrangente, a expansão da jurisdição constitucional e a ineficiência dos Poderes Legislativo e Executivo, foram causas seminais para a judicialização.

A percepção de Gunther Teubner sobre direito como sistema autopoiético, serve de paradigma para a compreensão da Judicialização da política (TEUBER, 1989)5. Segundo o autor, o direito é um subsistema

\footnotetext{
${ }^{4}$ No livro il diritto vivente destaca Eligio Resta (2008, p. 66) que "a identidade do direito, portanto, está toda na aposta de sua diferença em respeito a todos os outros sistemas (da moral, da religião, da economia, da ciência e assim por diante) e assim ele sobrevive se a sua linguagem é diferente das outras. Perde identidade caso se confunda com as outras linguagens, com os outros códigos, com os outros sistemas. Significa que as escolhas "normativas" do direito, sempre cognitivamente abertas, poderão tãosomente investir sobre os próprios códigos; também, senão sobretudo, quando estão em jogo "âmbitos" possíveis como o corpo, a vida, o bios".

${ }^{5}$ As bases da teoria de Gunther Teubner, advêm de uma reflexão profunda e crítica do modelo de sistema proposto pelo sociólogo Niklas Luhmann, que vislumbrou o direito como um sistema auto-referencial fechado. Para Gunther Teubner o "Direito retira a sua própria validade dessa auto-referência pura, pela qual qualquer operação jurídica reenvia para o resultado de operações jurídicas. Significa isto que a validade do Direito não pode ser importada do exterior do sistema jurídico, mas apenas obtida a partir do
} 


\section{DESJUDICIALIZAÇÃO DA SAÚDE , DIÁLOGOS INTERINSTITUCIONAIS E PARTICIPAÇÃO SOCIAL}

social autopoiético aberto, que se comunica com outros sistemas (econômicos, religiosos, políticos, etc.), aumentando, cumulativamente, sua relação circular, de forma gradativa, gerando um hiperciclo (TEUBER, 1989).

O fenômeno da juridificação foi observado pelo autor na Europa no período do Welfare State, em que se notava uma interferência da realidade externa no sistema jurídico. As transformações da sociedade refletiam na evolução do sistema autopoético do direito (TEUBER, 1989).

Ocorre que a interferência abusiva do Judiciário em questões políticas desestabiliza o próprio sistema e inviabiliza a concretização de inúmeros direitos sociais, de caráter eminentemente coletivo e não individual. Convém registrar que diversos estudos demonstram que a judicialização traz impactos negativos para a justiça distributiva e para o funcionamento da democracia (BARROSO, 2007; MACHADO, 2011; SILVA, 2014).

Esta afirmação decorre da tentativa de enfatizar a necessidade de concretização de um direito fundamental social, baseado no princípio da fraternidade, que implica na necessidade de ir além, muitas vezes, do direito individual para garantir o direito de todos (MARTINI, 2010)

Existem divergentes avaliações a respeito da repercussão do papel invasivo do direito nas instituições políticas. Há um eixo procedimentalista, em defesa de um Judiciário com poderes mais limitados ${ }^{6}$, e um eixo substancialista que preconiza uma participação mais efetiva do Judiciário nas democracias contemporâneas.

O contexto sócio-político do Brasil, coordenado por uma Constituição Dirigente $^{7}$, permitiu o redimensionamento do papel do Judiciário, com a consequente judicialização da política, mas essa intervenção deve ser excepcional e deve focar na natureza coletiva dos direitos materializados através de políticas públicas. Ademais, o Judiciário não pode se furtar ao diálogo e decidir unilateralmente no tocante a políticas públicas.

Com o escopo de racionalizar e combater o excesso de demandas judiciais o Conselho Nacional de Justiça permanece investindo na implementação de ferramentas técnicas que possam auxiliar os

seu interior. Nas palavras de Luhmann, "não existe direito fora do direito, pelo que sua relação com o sistema social, o sistema jurídico, não gera nem inputs nem outputs" (TEUBER, 1989, p. 02).

${ }^{6}$ A corrente procedimentalista é defendida, dentre outros autores, Junger Habermas e Niklas Luhmann. Cf. Habermas (2003).

7 “Nitidamente, a nossa Constituição Federal é dirigente, já que objetiva uma mudança social, indo além de representar um simples elenco de instrumentos de governos. Percebe-se esta característica, pois ela apresenta inúmeros programas/metas a serem atingidos pelo Estado e pela sociedade". (MARTINI, 2008, p. 284-285) 


\section{REVISTA ESTUDOS INSTITUCIONAIS}

JULHO/DEZEMBRO - ISSN 2447-5467

magistrados nas ações que envolvem direito à saúde. Em setembro de 2016 foi aprovada a resolução n. 238, que dispõe sobre a criação e a manutenção de comitês estaduais de saúde, bem como a especialização em comarcas com mais de uma vara de fazenda pública. O Comitê Estadual da Saúde terá entre as suas atribuições auxiliar os tribunais na criação de Núcleos de Apoio Técnico do Judiciário (NAT-JUS), constituído de profissionais da Saúde, para elaborar pareceres acerca da medicina baseada em evidências (BRASIL, 2016). Visando a contenção da judicialização, o Ministério da Saúde irá disponibilizar software para o controle das ações judiciais (DATASUS, 2017).

Observa-se que, não obstante a iniciativa do Conselho Nacional de Justiça para racionalizar a judicialização, ainda não existe um comportamento amplo do Judiciário no sentido de concretizar, com razoabilidade, o direito social à saúde.

Necessário, portanto, avaliar se o fenômeno inverso, ou seja, o da desjudicialização seria uma alternativa viável a concretização do direito à saúde na medida em que propugna diálogos interinstitucionais, mediações administrativas e uma maior participação da sociedade nas tomadas de decisão.

Ao se lançar um olhar sobre a realidade nacional, constata-se que a judicialização da saúde não conseguiu dar uma resposta efetiva à sociedade. Esta constatação foi alcançada a partir da leitura dos relatórios produzidos pelo Observatório de Análise Política em Saúde (OAPS, 2017) que retrata o crescente aumento do número das ações judiciais e o descompasso com a efetivação do direito na prática.

Deve-se reconhecer que, na solução de questões que envolvem política de Estado ou de Governo, é mister oportunizar às partes envolvidas o tratamento do conflito de forma extrajudicial, através da mediação e do diálogo. Não se quer com isso defender que as políticas governamentais, consideradas isoladamente, serão suficientes para uma boa prestação de serviços de saúde, mas sim a necessidade de criar alternativas dialógicas e com maior participação da sociedade para a concretização do direito à saúde.

Já se vislumbra no plano prático e operacional um incremento por parte do Poder Público na organização do sistema com a valorização da Comissão Nacional de Incorporação de Tecnologias (Conitec) no Sistema Único de Saúde de modo a viabilizar a inclusão, exclusão ou alteração de tecnologias em saúde pelo SUS, bem como na constituição ou alteração de Protocolos Clínicos e Diretrizes Terapêuticas - PCDT (BRASIL, 2011).

Alexandre Barbosa da Silva e Gabriel Schulman (2017) destacam a importância da desjudicialização da saúde, especialmente quando: (i) o medicamento está na Relação Nacional de Medicamentos Essenciais 


\section{DESJUDICIALIZAÇÃO DA SAÚDE , DIÁLOGOS INTERINSTITUCIONAIS E PARTICIPAÇÃO SOCIAL}

(RENAME) pois a concessão é imperativa; (ii) quando o custo do tratamento é baixo e sua eficácia já está demonstrada; (iii) quando há alternativa terapêutica para o tratamento do paciente; (iv) quando o uso do Núcleo de Apoio Técnico (NAT) dos tribunais ou do CNJ conclui antes da ação judicial pela absoluta adequação do pleito.

Não bastasse isso, a desjudicialização fomenta maior participação da sociedade no debate público de concretização do direito à saúde. Essa participação vem sendo incentivada através de audiências públicas e inserção nos conselhos. Em dezembro de 2017, por exemplo, o Supremo Tribunal Federal realizou audiência pública com o tema "Justiça e Saúde" que contou com a participação de 32 entidades e personalidades (CNJ, 2017). Referida audiência foi designada para atender a demanda dos próprios usuários do Sistema Único de Saúde, de gestores públicos, autoridades dos Poderes da República, além da comunidade acadêmica.

Como é possível observar a desjudicialização permitirá o debate da sociedade nas questões políticas democratizando a interpretação constitucional ${ }^{8}$ e permitindo o melhor tratamento do litígio, na medida em que é um fenômeno contrário à judicialização, ao priorizar tratamentos alternativos e dialógicos para litígios que envolvam políticas públicas de saúde.

\section{O PRINCÍPIO DA FRATERNIDADE E A DESJUDICIALIZAÇÃO DA POLÍTICA PÚBLICA DE SAÚDE}

O estudo da fraternidade enquanto princípio jurídico ${ }^{9}$ é uma exigência da contemporaneidade em face da constatação da necessidade de uma teoria que se encarregue das lutas por reconhecimento, da afirmação de identidades coletivas e da inclusão do "outro" no Estado Democrático de Direito (HABERMAS, 2002, p. 230). Esta busca de reconhecimento é mal compreendida, ou mesmo rejeitada, pelos que são inspirados por uma

\footnotetext{
8 Segundo Häberle (1997, p. 14) a teoria da interpretação deve ser garantida sob a influência da teoria democrática. Desta maneira "é impensável uma interpretação da Constituição sem o cidadão ativo e sem as potências públicas".

${ }^{9}$ Na percepção de Eligio Resta (2008, p. 43) "o direito, e este é o nosso tema, apresentase por sua vez como um grande campo de observação: quanto mais se quer o reduzir a uma dimensão unitária e monologante, tanto mais se dá conta das tantas outras coisas que ele é e as tantas "práticas" sociais que representa; em regra as mais contraditórias. Por todos, um exemplo. Quanto mais, quase cartesianamente, os códigos modernos falam da integridade do corpo, tanto mais se assiste a um processo de decomposição progressiva das "partes" do corpo, que podem ser doadas, na prática vendidas, reduzidas a objeto de commodification".
} 


\section{REVISTA ESTUDOS INSTITUCIONAIS}

JULHO/DEZEMBRO - ISSN 2447-5467

visão solipsista, intelectual e voluntarista da identidade individual, mas encontra respaldo nas sociedades democráticas e no constitucionalismo contemporâneo.

Em verdade, fraternidade é princípio jurídico que tem, essencialmente, quatro funções: função de equilíbrio entre liberdade e igualdade, função de reconhecimento, desveladora de paradoxos e função interpretativa (MACHADO, 2017). Destaca-se, para esse artigo, a função de reconhecimento da fraternidade que explicita a alteridade e a intersubjetividade no direito ${ }^{10}$, impondo-se do sujeito de direito um olhar para o outro, o respeito às diversidades numa sociedade multicultural (processo de inclusão), o espírito de tolerância, de compreensão mútua e de solidariedade.

Para reconhecer o outro, é necessário, antes, identificar-se consigo mesmo porque "a personalidade só começa quando o sujeito tem consciência de si" (HEGEL, 1997, p. 41). A fraternidade então se constitui em processo dialético entre consciência e liberdade. Ou seja, a consciência guia a liberdade para o exercício da fraternidade no sistema jurídico ${ }^{11}$.

A fraternidade se apresenta de forma dialética integrada com a possibilidade do ser em comunhão com o outro numa perceptiva formada a partir da alteridade (ANDRADE, 2010) como dado fundamental para a concretização de direitos. Para tanto, revela a consciência de si e do outro possibilitando perceber a unidade constitucional existente nos direitos fundamentais que giram em torno da dignidade humana.

A reestruturação da ordem econômica e social em face da modernidade líquida, para utilizar a expressão de Bauman (2003), faz com que a contemporaneidade necessite de novos paradigmas culturais e constitucionais que possibilitem a concretude dos direitos fundamentais.

Ao descrever as relações sociais, Bauman (2003) assinala como a cultura condiciona as interações humanas e auxilia o modo de percepção da complexidade social em que a função jurisdicional está imersa. A

\footnotetext{
10 Seguindo mais uma vez os ensinamentos de Eligio Resta (2008, p. 27) "A "vida" do direito portanto é um grande recipiente no qual se vertem todas as semânticas influentes que a linguagem do tempo sedimenta, alargando e restringindo, enfatizando ou dissolvendo caracteres particulares da experiência jurídica. Em todo caso, porém, pode-se concluir, a vida do direito se constitui sempre como "irredutibilidade" da experiência".

11 Como indica Maria Inês Chave de Andrade (2010, p. 136), a razão fraterna está "articulada por meio de um conjunto de princípios e ideias segundo as quais pensamos o mundo, sendo antes a realidade profunda das coisas, a essência do próprio ser".
} 


\section{DESJUDICIALIZAÇÃO DA SAÚDE , DIÁLOGOS INTERINSTITUCIONAIS E PARTICIPAÇÃO SOCIAL}

construção garantista, por exemplo, assinala o movimento de ideias entre política e direito em face da ordem democrática.

A reconfiguração constitucional do garantismo, na sua expressão máxima, manifesta na teoria garantista de Luigi Ferrajoli (2010), redimensiona as relações entre direito subjetivo e estrutura normativa garantidora dos direitos fundamentais e possibilita inserir, nesse trânsito de ideias, a dialética da fraternidade.

Desse modo, observa-se na ordem social em que tais direitos se encontram instituídos o papel fundamental do Poder Judiciário na esfera constitucional. Neste contexto, Ferrajoli atenta para os aspectos da judicialização de modo que a garantia da jurisdição constitucional tem seu caráter integrado aos problemas sociais no contexto de aplicação dos direitos fundamentais.

Apesar disso, conforme sublinhado no tópico anterior, quando se trata de questão de políticas públicas, não se pode afastar a importância da participação das partes no tratamento do conflito para construção da melhor resposta para o problema apresentado, apresentando-se a desjudicialização como uma alternativa possível, numa perspectiva voltada para o princípio da fraternidade.

A questão fraterna trata, através da desjudicialização, a dificuldade de integração dos grupos sociais, de modo que a fraternidade no direito percorre distintos níveis e dimensões sócio jurídicas, no plano interno e externo, integrando distintos âmbitos do conhecimento dentre os quais o aspecto epistemológico, político e constitucional.

Neste contexto, a dialética da fraternidade incorpora as realidades psicoculturais das práticas sociais na medida em que contém em si mesma o exercício da cidadania. Disso resulta a ampliação de horizontes da práxis jurídica através da compreensão dos artefatos produtores da legitimidade no contexto da inter-relação entre o sistema constitucional normativista e o constitucionalismo democrático.

A lei no 13.105, de 16 de março de 2015, que instituiu o Código de Processo Civil, por exemplo, dialoga com o princípio da fraternidade ao estimular, de diversas maneiras, formas consensuais para tratamento dos conflitos, como ocorre na mediação e conciliação em que deve haver um reconhecimento recíproco das partes e uma solução pacífica do litígio. Da mesma forma, a lei 13.140 de 26 de junho de 2015, ao dispor sobre a mediação entre particulares como meio de solução de controvérsias e a autocomposição de conflitos no âmbito da administração pública deve ser orientada pela fraternidade de modo a alcançar o tratamento do conflito. 


\section{REVISTA ESTUDOS INSTITUCIONAIS}

Especificamente em relação à desjudicialização da saúde a partir do princípio da fraternidade, defende-se maior cooperação entre entes a partir de definição de estratégias conjuntas para a garantia do direito. Uma importante medida para esse objetivo foi a publicação da Resolução n⿳0 20, de 27 de julho de 2017, pela Comissão Intergestores Tripartite (CIT), a qual "Dispõe sobre a internalização do Sistema S-Codes e a cooperação entre entes na gestão dos impactos da judicialização da saúde, a partir da definição de diretrizes e estratégias comuns de atuação para a organização de fluxos, informações e procedimentos" (CIT, 2017).

\section{Desjudicialização da SAÚde, Diálogos INTERINSTITUCIONAIS E PARTICIPAÇÃO SOCIAL}

Diante das transformações sociais, que enfatiza princípios humanistas do cooperativismo e da responsabilidade ética nas relações jurídicas com aplicação do princípio da fraternidade, pode-se afirmar que a desjudicialização do direito à saúde é uma alternativa à efetivação do direito? $\mathrm{O}$ direito de produto da vida se torna regulador da própria vida $^{12}$ ?

Pretende-se, portanto, neste último tópico demonstrar alguns instrumentos de desjudicialização que possam concretizar o direito à saúde. Não se quer com isso afastar o princípio da inafastabilidade do controle jurisdicional, mas objetiva-se fomentar, à luz do princípio da fraternidade, ações extrajudiciais e de cooperação, a partir da utilização de práticas mediadoras.

Ao trabalhar com a temática da desjudicialização Alexandre Barbosa da Silva e Gabriel Schulman destacaram sintomas do modelo autal que precisam ser superados, a saber:

${ }^{12}$ Qual é então a outra maneira de pensar em respeito à potência ilimitada, esta máquina auto-desejosa da tecnologia? Pode ser a ética, ou a economia, ou o direito; cada um destes a seu modo afirma que não podemos fazer aquilo que podemos fazer? Se o código da tecnologia é aquele do "poder fazer" aquilo que, com uma eloquente tautologia, a mesma tecnologia pode fazer, medindo-se exclusivamente com as suas próprias possibilidades, que são sempre meramente provisórias e, de seu ponto de vista, cumulativamente progressivas, dever-se-ia pretender a partir dos outros códigos se poder regular, interromper, controlar o "poder fazer". A economia o faria de seu ponto de vista, a ética e o direito dos seus. Se houvessem exclusivamente antagonismos e antiteticidades se deveria então pretender que, por exemplo, o direito ou a ética se colocassem como potências simetricamente opostas, mas somente mais fortes de que a própria tecnologia. Para tanto deveriam simplesmente se pensar, e ser, mais "poderosas" que esta. (RESTA, 2008, p. 73) 


\section{DESJUDICIALIZAÇÃO DA SAÚDE , DIÁLOGOS \\ INTERINSTITUCIONAIS E PARTICIPAÇÃO SOCIAL}

1) prevalência de solução judicial diante de negativas, com grande número de ações individuais; 2) elevados custos não relacionados a tratamentos estruturados para atender o sistema; 3) ônus do tempo na disponibilização do medicamento ou tratamento; 4) diálogo insuficiente entre entes públicos e privados e entre diferentes esferas da administração pública; e 5) sobreposição de avaliações médicas independentes (SILVA; SCHULMAN, 2017).

Quanto ao grande número de ações individuais cumpre tecer algumas considerações. De fato, é necessário compreender que na conjuntura do constitucionalismo contemporâneo, aqui identificado como constitucionalismo fraterno (BRITTO, 2007), deve-se relativizar a compreensão individualista dos direitos fundamentais sociais, relacionada à justiça comutativa, para incutir a dimensão da fraternidade, de caráter distributivo.

Dito de outra forma, a visão utilitarista dos direitos fundamentais deve ser afastada para alcançar a sua dimensão fraternal. Pensar em sentido diverso pode dificultar a realização da justiça social, que indica, entre outros aspectos, a necessidade de elaboração e de execução de políticas públicas voltadas à inclusão social e à concretização de direitos fundamentais.

Assim, partindo-se do pressuposto da existência de uma justiça social de fato, tem-se uma sociedade que inclui todos somente porque também é possível, ao mesmo tempo, excluir os "ditos" incluídos. Esse problema deve ser afrontado também pelos economistas, tendo em mente a perspectiva da justiça, mas não no sentido utilitarista. Não se pode esquecer que o utilitarismo tem, ainda, uma grande influência nos definidores de políticas públicas, tanto nacionais quanto internacionais. (MARTINI, 2006, p. 131)

Em verdade, a efetivação da justiça distributiva revela um dos objetivos do constitucionalismo fraterno, razão pela qual convém estimular as ações coletivas ou a instrumentalização de demandas repetitivas para uniformização das decisões e a racionalização do sistema. Diante desta perspectiva é que o Superior Tribunal de Justiça conclui o julgamento de recurso repetitivo (REsp no 1.657 .156 - RJ), de relatoria do Ministro Benedito Gonçalves, que determina quais são os requisitos para que o Poder Judiciário determine o fornecimento de medicamentos fora da lista do SUS. A tese fixada uniformizou o entendimento a ser observado em primeiro grau em razão do art. 1040 do Código de Processo 


\section{REVISTA ESTUDOS INSTITUCIONAIS}

JULHO/DEZEMBRO - ISSN 2447-5467

Civil de que constitui obrigação do poder público o fornecimento de medicamentos não incorporados em atos normativos do SUS, desde que reunidos, cumulativamente, os seguintes requisitos (BRASIL, 2018):

(i) A comprovação, por meio de laudo médico fundamentado e circunstanciado expedido por médico que assiste o paciente, da imprescindibilidade ou necessidade do medicamento, assim como da ineficácia, para o tratamento da moléstia, dos fármacos fornecidos pelo SUS;

(ii)Incapacidade financeira do paciente de arcar com o custo do medicamento prescrito; e

(iii)Existência de registro do medicamento no cadastro da Agência Nacional de Vigilância Sanitária (ANVISA).

Nesta decisão, além da definição de critérios para balizar os julgamentos das instâncias inferiores, o Superior Tribunal de Justiça estabeleceu que depois de transitada em julgado a decisão em cada caso concreto (envolvendo a obrigação de dispensação de fármacos não constantes nas "listas" do SUS), o Ministério da Saúde e a Comissão Nacional de Tecnologias do SUS fossem comunicados para o efeito de procederem a estudos sobre a viabilidade de serem os medicamentos pleiteados incorporados às prestações a serem disponibilizadas pelo SUS. Sobre esse aspecto Ingo Wolfgang Sarlet sublinhou:

Com tal provimento - que é de se aplaudir - o STJ, sem impedir em si o ajuizamento de ações individuais , embutiu um elemento vinculado à dimensão transindividual do direito à saúde, visto que a incorporação dos medicamentos pleiteados ao SUS (caso aprovada pelos estudos realizados) implica a sua disponibilização em caráter geral, atendendo ao dever constitucional cometido ao poder público de assegurar o acesso igualitário e universal aos bens e serviços em saúde. Que isso também acaba por inibir demandas individuais, por sua vez, dependerá do cumprimento pelo Estado de sua obrigação, pois não faltam casos (pelo contrário, trata-se mesmo da maioria) nos quais o que se busca em Juízo é pura e simplesmente que o Estado dispense aquilo que deve fornecer com base na lei e no SUS. Nesse sentido, é possível afirmar que a decisão do STJ assumiu o caráter de uma decisão de 


\title{
DESJUDICIALIZAÇÃO DA SAÚDE , DIÁLOGOS \\ INTERINSTITUCIONAIS E PARTICIPAÇÃO SOCIAL
}

\begin{abstract}
natureza estruturante, pois não impôs a incorporação do medicamento, mas sim, limitou-se a determinar mediante um diálogo de natureza institucional - que o Poder Executivo promova os estudos técnicos pertinentes de modo a averiguar da conveniência e mesmo necessidade de tal incorporação. (SARLET, 2018)
\end{abstract}

Outro sintoma que merece destaque é a ausência de diálogo entre os entes. Inelutavelmente, para que haja efetividade do direito à saúde, de caráter transindividual, é mister a cooperação entre os poderes e a participação da sociedade. Ou seja, os conteúdos da integralidade e da assistência do sistema devem ser definido entre sociedade e Estado, numa contínua cooperação por meio de diálogos interinstitucionais. O princípio da cooperação define, dentre outros aspectos, o modo como os poderes públicos e as partes envolvidas devem atuar no Estado Democrático. Surgem, destarte, deveres de conduta tanto para os Poderes Públicos como para toda a sociedade, decorrentes do princípio responsabilidade (JONAS, 2006).

Compreende-se que para efetivar uma política de saúde adequada, é mister que os atores envolvidos nela participem do processo desde sua gestão até sua implementação. É neste sentido que o direito à saúde pode ser resgatado e efetivado, pois não basta dizer que a saúde é um direito do cidadão e um dever do estado, é preciso criar condições para que este direito seja efetivado, e isso se dará somente por meio de políticas públicas que respeitem as diferenças loco-regionais, mas que apresentem uma estrutura global, pois os problemas de saúde não são territorialmente limitados. (MARTINI, 2009).

Nesse ambiente, o componente democrático, a partir da efetiva participação dos cidadãos, é fundamental para máxima efetivação do princípio da cooperação, que deve ser observado em todas as etapas das políticas públicas, desde a formação até o controle. É da multiplicidade de opiniões e de interesses da sociedade que será elaborado o planejamento geral dos recursos públicos, direcionando os investimentos para setores priorizados pela própria comunidade. Somente assim será legítima a escolha para construção de determinada política pública em detrimento de outra no Estado Democrático.

À guisa de exemplo, as fases para implementação das políticas públicas necessárias à realização do direito à saúde devem ser construídas a partir da cooperação. Ou seja, é necessário que, no momento da formação, execução, avaliação e controle da política pública, se abstraiam os pensamentos individualistas de cada ente público para, a 


\section{REVISTA ESTUDOS INSTITUCIONAIS}

JULHO/DEZEMBRO - ISSN 2447-5467

partir do diálogo, encontrar a melhor resposta para a coletividade. Vê-se, portanto, a relevância do diálogo interinstitucional.

Ademais, no relacionamento entre fraternidade e políticas públicas de saúde, parece correto defender que soluções extrajudiciais (desjudicializadas) baseadas no diálogo entre os poderes e a comunidade sejam mais céleres e, muitas vezes, mais eficazes do que as intervenções jurisdicionais.

A mediação administrativa pode ser um instrumento eficaz para a concretização do direito à saúde, uma vez que cria espaços de debate extrajudicial. Nessa linha de raciocínio, Alexandre Barbosa da Silva e Gabriel Schulman (2017, p. 294) defendem que para a mediação administrativa "deve-se ter em mente a possibilidade de espações administrativos que avaliem especificamente os casos concretos dos pacientes e possam aferir a necessidade (ou não) de se liberar tratamentos para além dos protocolos clínicos".

Por certo, em diversas situações, a melhor alternativa é a articulação das partes com vistas a estabelecer um compromisso ou efetuar uma transação. Sufragando essa linha de raciocínio, José Reinaldo de Lima Lopes (2006, p. 168) esclarece: "as soluções de compromisso, a elaboração de propostas a serem cumpridas ao longo de certo prazo, não são 'a segunda opção', não são apenas a solução 'na falta de solução melhor': quero dizer que em vários casos são exatamente a solução própria".

A fim de viabilizar o diálogo interinstitucional a mediação administrativa deve contar com a participação do Ministério Público, da Defensoria Pública e dos entes envolvidos nas competências de oferta dos procedimentos e fármacos (SILVA, SCHULMAN, 2017)

No âmbito do Supremo Tribunal Federal permanecem os debates sobre a obrigatoriedade do custeio, pelo Poder Público, dos medicamentos de alto custo e complexidade e dos que não têm registro da ANVISA. Nesse ponto, convém registrar os recursos extraordinários 566471 e 657718, de relatoria do Ministro Marco Aurélio (BRASIL, 2016). O RE 566.471/RN trata da dispensação de medicamentos de alto custo não incorporados pelo SUS e o RE 657.715/MG discute os casos de medicamentos sem registro da Anvisa (BRASIL, 2016). Já foi reconhecida a Repercussão Geral da matéria, mas o julgamento ainda não foi encerrado.

Ao proferir voto-vista no RE 657.718/MG o ministro Luís Roberto Barroso avaliou ser necessário desjudicializar o debate sobre saúde no Brasil, aduzindo que o Poder Judiciário não é a instância adequada para a definição de políticas públicas de saúde, razão pela qual o Poder Judiciário só deveria interferir em situações extremas ou quando a intervenção consiste unicamente em efetivar políticas públicas já 


\section{DESJUDICIALIZAÇÃO DA SAÚDE , DIÁLOGOS INTERINSTITUCIONAIS E PARTICIPAÇÃO SOCIAL}

formuladas pelo Sistema Único de Saúde. No seu voto-vista, Barroso propôs cinco requisitos cumulativos, que devem ser observados pelo Poder Judiciário para o deferimento de determinada prestação de saúde: $\left.1^{\underline{o}}\right)$ incapacidade financeira de arcar com o custo correspondente; $2^{\underline{o}}$ ) demonstração de que a não incorporação do medicamento não resultou de decisão expressa dos órgãos competentes; $3^{\circ}$ ) inexistência de substituto terapêutico incorporado pelo SUS; $4^{\circ}$ ) comprovação de eficácia do medicamento pleiteado à luz da medicina baseada em evidências; $5^{\circ}$ ) propositura da demanda necessária em face da União, já que a responsabilidade pela decisão final sobre a incorporação ou não de medicamentos é exclusiva desse ente federativo (BRASIL, 2016).

Outro ponto que deve ser destacado no voto do ministro é a necessidade de realização de diálogo entre o Poder Judiciário e entes ou pessoas com expertise técnica na área de saúde, como as câmaras e núcleos de apoio técnico, profissionais do SUS e Conitec. Tal diálogo demonstra a preocupação do Supremo Tribunal federal com a interferência desarrazoada do Judiciário nas políticas públicas de saúde.

Decerto, deve-se ter em mente que o papel do Judiciário não é substituir o Legislativo ou o Executivo na elaboração e execução de políticas públicas, mas cooperar com esses poderes a fim de alcançar e materializar o princípio jurídico da cooperação e da fraternidade.

Para além disso, o princípio da fraternidade contribuirá para que haja cooperação da sociedade e dos Poderes Públicos na concretização do direito à saúde. Por certo, ao se conscientizar a sociedade da responsabilidade ética social, haverá uma maior participação nas decisões de políticas públicas, uma vez que o indivíduo projetará no outro sua própria necessidade.

Parece consentâneo sustentar, em face da necessidade de cooperação entre os poderes e da sociedade para atendimento do direito à saúde, que se busque métodos alternativos de tratamento de litígio com participação das partes envolvidas para as escolhas e implementações das políticas públicas de saúde. Desta forma, viabiliza-se o diálogo entre os poderes e a mensuração do impacto financeiro do pedido, além de verificar, adrede, a possibilidade orçamentária.

Em razão do caráter coletivo e distributivo do direito à saúde, tal direito deve ser afirmado por políticas públicas e não por decisões judiciais. $\mathrm{O}$ conhecimento das necessidades sociais da comunidade, da melhor técnica para distribuição de recursos escassos, e das possibilidades orçamentárias é essencial para definir políticas públicas voltadas à concretização do direito à saúde. Decisão judicial sobre a exigibilidade do direito à saúde, que ignora estas circunstâncias, pode 


\section{REVISTA ESTUDOS INSTITUCIONAIS}

JULHO/DEZEMBRO - ISSN 2447-5467

causar problemas sociais maiores do que os que estão sendo tutelados, pois provoca redistribuição indireta de recursos de políticas públicas e nem sempre garante o princípio da fraternidade.

Os canais de participação cidadã na formação de políticas públicas de saúde pela via extrajudicial são importantes para o fenômeno da desjudicialização. A inclusão de medicamento no RENAME, por exemplo, é uma decisão dotada de respaldo deliberativo e democrático, daí porque a inclusão judicial de medicamento não garante o respeito à ordem democrática. Melhor seria que demandas judiciais de caráter coletivo que discutissem a inclusão de novos medicamentos no RENAME fossem levadas para deliberação da sociedade por meio de audiências públicas. Assim garantiria ao mesmo tempo o diálogo interinstitucional e a participação social.

Defende-se, portanto, que instrumentos para desjudicialização da saúde como mediação administrativa, diálogo interinstitucional e maior participação da sociedade nas tomadas de decisão mostram-se como alternativas viáveis para a efetivação do direito à saúde. Certamente, não será um processo rápido pois depende de uma mudança cultural, mas deve-se defender métodos alternativos como forma de efetivar o direito e garantir a justiça social.

\section{CONCLUSÕES}

O processo de desjudicialização representa tendência atual e que envolve mudança cultural e jurídica, já que os processos judiciais e os gastos com saúde têm aumentado, mas não têm sido resolutivos, nem têm resolvido o problema das desigualdades sociais, as quais impactam diretamente na saúde.

Evidentemente, a aplicação do princípio da fraternidade na sua função de reconhecimento e de responsabilidade social demanda transformação da própria sociedade e dos poderes públicos envolvidos pois a fraternidade representa um âmbito biopolítico entre o direito e a vida, o que significa estabelecer formas normativas e regras de vida, as quais podem ser compartilhadas com uma vida em comum, uma vida que torna todos não somente iguais, mas cria uma verdadeira comunidade que co-divide.

De tudo o que foi exposto neste artigo compreende-se que a judicialização da saúde deve ser excepcional e não pode perder de vista que a intervenção em política pública de saúde envolve demandas distributivas de caráter plurilateral (o vencedor não pode excluir o perdedor), e não conflitos comutativos de feição bilateral (um ganha e o outro perde). 


\section{DESJUDICIALIZAÇÃO DA SAÚDE , DIÁLOGOS INTERINSTITUCIONAIS E PARTICIPAÇÃO SOCIAL}

O caráter plurilateral do conflito distributivo reflete o princípio da fraternidade, razão pela qual sustentou-se a desjudicialização da saúde como alternativa à efetivação do direito, a partir da participação efetiva da comunidade nos conselhos sociais, nas audiências públicas, e por meio do diálogo interinstitucional.

\section{REFERÊNCIAS}

ANDRADE, Maria. A fraternidade como direito fundamental entre o ser e o dever ser na dialética dos opostos de Hegel. Coimbra: Edições Almedina, 2010.

AQUINI, Marco. Fraternidade e direitos humanos. In: BAGGIO, Antonio Maria (Org.). O princípio esquecido/1: A fraternidade na reflexão atual das ciências políticas. Trad. Durval Cordas, Iolanda Gaspar, José Maria de Almeida. São Paulo: Cidade Nova, 2008.

BAGGIO, Antonio Maria. O Princípio Esquecido/1: A fraternidade na reflexão atual das ciências políticas. Traduções Durval Cordas, Iolanda Gaspar; José Maria de Almeida. Vargem Grande Paulista - SP: Cidade Nova, 2008.

BAGGIO, Antonio Maria. O Princípio Esquecido/2: Exigências, recursos e definições da fraternidade na política. Traduções Durval Cordas, Luciano Menezes Reis. Vargem Grande Paulista - SP: Cidade Nova, 2009.

BAUMANN, Zigmun. A modernidade liquida. Trad. Mirta Rosenberg. México: Fondo de Cultura Econômica, 2003.

BRASIL. Tribunal de Contas da União (TCU). Auditoria operacional. Fiscalização de orientação centralizada (FOC). Judicialização da saúde. Identificar o perfil, o volume e o impacto das ações judiciais na área da saúde [...]. Acórdão no 1787/2017. 2017 (2017a). Brasília-DF. Relator: Ministro Bruno Dantas. Pesquisa de jurisprudência. Disponível em: 


\section{REVISTA ESTUDOS INSTITUCIONAIS}

JULHO/DEZEMBRO - ISSN 2447-5467

$<$ https://contas.tcu.gov.br/pesquisaJurisprudencia/\#/detalhamento/11/\% 252a/NUMACORDAO\%253A1787\%2520ANOACORDAO\%253A2017/D TRELEVANCIA\%2520desc\%252C\%2520NUMACORDAOINT\%2520des c/false/1/false>. Acesso em: 10 jul. 2018.

BRASIL. Conselho Nacional de Justiça. Resolução n. 238, de 06/09/2016. 2016. Disponível em: $<$ http://www.cnj.jus.br/busca-atosadm?documento=3191>. Acesso em: 20 jul. 2018.

BRASIL. Conselho Nacional de Justiça. Audiência Pública sobre prestação da jurisdição em processos relativos à saúde. 2017 (2017b). Disponível em: <http://www.cnj.jus.br/campanhas/455-acoes-eprogramas/programas-de-a-a-z/forum-da-saude/85804-audienciapublica-sobre-prestacao-da-jurisdicao-em-processos-relativos-a-saude $>$. Acesso em: 12 jul. 2018.

BRASIL. Conselho Nacional de Justiça (CNJ). Justiça em números 2017. 2017 (2017c) Disponível em:

<http://www.cnj.jus.br/files/conteudo/arquivo/2017/12/b60a659e5d5cb79 337945c1dd 137496c.pdf>. Acesso em: 10 jul. 2018.

BRASIL. Comissão Intergestores Tripartite (CIT). Resolução no 20, de 27 de julho de 2017. Dispõe sobre a internalização do Sistema S-Codes e a cooperação entre entes na gestão dos impactos da judicialização da saúde, a partir da definição de diretrizes e estratégias comuns de atuação para a organização de fluxos, informações e procedimentos. 2017 (2017c). Disponível em:

<http://www.lex.com.br/legis_27478564_RESOLUCAO_N_20_DE_27_D E_JULHO_DE_2017.aspx>. Acesso em: 15 jul. 2018.

BRASIL. Decreto nº 7.646, de 21 de dezembro de 2011_. Dispõe sobre a Comissão Nacional de Incorporação de Tecnologias no Sistema Único de Saúde e sobre o processo administrativo para incorporação, exclusão e alteração de tecnologias em saúde pelo Sistema Único de Saúde - SUS, 


\section{DESJUDICIALIZAÇÃO DA SAÚDE , DIÁLOGOS INTERINSTITUCIONAIS E PARTICIPAÇÃO SOCIAL}

e dá outras providências. Disponível em:

$<$ http://www.planalto.gov.br/CCIVIL_03/_Ato2011-

2014/2011/Decreto/D7646.htm>. Acesso em: 27 jul. 2018.

BRASIL. Superior Tribunal de Justiça. RESP n. 1.657.156 - RJ. Disponível em:

$<$ https://ww2.sti.jus.br/websecstj/cgi/revista/REJ.cgi/ITA?seq=1641175\&ti po $=0 \&$ nreg $=201700256297 \& S e q C g r m a S e s s a o=\&$ CodOrgaoJgdr $=\& d t=201$ 80504\&formato=PDF\&salvar=false $>$. Acesso em: 27 jul. 2018.

BARROSO, Luís Roberto. Da falta de efetividade à judicialização excessiva: direito à saúde, fornecimento gratuito de medicamentos e parâmetros para a atuação judicial. Interesse Público. Belo Horizonte, v. 9, n. 46, nov. 2007. Disponível em:

$<$ http://bdjur.stj.jus.br/dspace/handle/2011/38245>. Acesso em 05 jul. 2018.

BRITTO, Carlos Ayres. Teoria da Constituição. Rio de Janeiro: Forense, 2003; Britto, Carlos Ayres. O humanismo como categoria constitucional. Belo Horizonte: Forum, 2007.

DE GIORGI, Raffaele. Direito, Tempo e Memória. Tradução Guilherme Leite Gonçalves. São Paulo: Quartier Latin, 2006.

DEPARTAMENTO DE INFORMÁTICA DO SUS (DATASUS).

Ministério da Saúde vai disponibilizar software para controlar ações judiciais em saúde. 2017. Disponível em:

$<$ http://datasus.saude.gov.br/noticias/atualizacoes/1105-ministerio-dasaude-vai-disponibilizar-software-para-controlar-acoes-judiciais-emsaude>. Acesso em 22 jul. 2018.

FERRAJOLI, Luigi. Estado Social y Estado de Derecho. In: ABRAMOVICH, Victor; AÑÓN, Maria José; COURTIS, Christian 


\section{REVISTA ESTUDOS INSTITUCIONAIS}

(comps). Derechos sociales - instrucciones de uso. México: Distribucciones Fontamara, 2003.

FERRAJOLI, Luigi. Costituzionalismo principialista e costituzionalismo garantista. Giurisprudenza Costituzionale, v. 55 , n. 3 , p. 2771-2817, 2010.

HÄBERLE, Peter. Hermenêutica Constitucional. A sociedade aberta de intérpretes da constituição: contribuição para a interpretação pluralista e "procedimental" da constituição. Trad. Gilmar Ferreira Mendes. Porto Alegre: Sergio Antonio Fabris, 1997.

HABERMAS, Jünger. Direito e democracia: entre facticidade e validade. Vol. 1. 2. ed. Tradução Flávio Beno Siebeneicher. Rio de Janeiro: Tempo Brasileiro, 2003.

HEGEL, Georg Wilhelm Friedrich. Princípios da filosofia do direito. São Paulo: Martins Fontes, 1997.

JONAS, Hans. O Princípio Responsabilidade: ensaio de uma ética para a civilização tecnológica. Tradução: Marijane Lisboa, Luiz Barros Montex. Rio de Janeiro: Contraponto. Ed. PUC-Rio, 2006.

LOPES, José Reinaldo de Lima. Direitos sociais: teoria e prática. São Paulo: Método, 2006.

MACHADO, Carlos Augusto Alcântara. A Fraternidade como categoria jurídico-constitucional. Revista Brasileira de Direito Público - RBDP. Belo Horizonte, ano 7, n. 26. jul/set. 2009, p. 33-54.

MACHADO, Clara. O princípio jurídico da fraternidade. Rio de Janeiro: Lumen Juris, 2017. 


\section{DESJUDICIALIZAÇÃO DA SAÚDE, DIÁLOGOS INTERINSTITUCIONAIS E PARTICIPAÇÃO SOCIAL}

MACHADO, Clara. Limites ao Ativismo Judicial à Luz do

Constitucionalismo Fraterno. Revista Baiana de Direto , n. 5, Salvador 2011.

MARTINI, Sandra Regina. Direito fraterno na sociedade cosmopolita. RIPE - Revista do Instituto de Pesquisas e Estudos, Bauru, v. 1, n. 46, p. 119-134, jul./dez. 2006.

MARTINI, Sandra Regina; OLIVEIRA, Christiano Augusto Seckler de. O direito à saúde e os determinantes sociais. Revista da Defensoria Pública, ano 1, n. 1, jul/dez 2008. Edição Especial Temática sobre Direito à saúde, v. 2, p. 284-285.

MARTINI, Sandra Regina. Saúde: um direito fundado na fraternidade. In: Fundação Oswaldo Cruz, Núcleo de Estudos em Direitos Humanos e Saúde Helena Besserman. Saúde e direitos humanos, ano 5, n. 5 (2008). Brasília: Editora do Ministério da Saúde, 2009.

MARTINI, Sandra Regina. Diritto fraterno, movimenti sociali e Beni comuni a tutta l'umanità: chi è il proprietário se el bene è di tutti?. Stato e diritti nell' età della globalizzazione. Salerno: Brunolibri, 2010, p. 7189 .

MATURANA, Humberto. La Democracia es uma obra de arte. Bogotá: Ed Magisterio, 1995.

PIZZOLATO, Filippo. Il principio constitucionale di fraternità: intinerario di ricerca a partire dalla Constituzione Italiana . Roma: Città Nuova, 2012.

RESTA, Eligio. O Direito Fraterno. Tradução Sandra Regina Martini Vial (Coord.). Santa Cruz do Sul-RS: EDUNISC, 2004. 


\section{REVISTA ESTUDOS INSTITUCIONAIS}

RESTA, Eligio. Il diritto vivente. 1 ed. Bari: Gius, Laterza e Figli, 2008.

SARLET, Ingo Wolfgang. STJ, STF e os critérios para fornecimento de medicamentos (parte 2). Consultor Jurídico. Disponível em: $<$ https://www.conjur.com.br/2018-mai-11/direitos-fundamentais-stj-stfcriterios-fornecimento-medicamentos-parte>. Acesso em: 29 jul. 2018.

SILVA, Alexandre Barbosa da. A intervenção do judiciário nas políticas públicas de saúde: elementos de (não) justicação constitucional. In: MEZZAROBA O et al. (Org.). Direitos sociais e políticas públicas I. Curitiba: Clássica, 2014, v. 25, p. 465-494.

SCHULMAN, Gabriel; DA SILVA, Alexandre Barbosa. (Des) judicialização da saúde: mediação e diálogos interinstitucionais. Revista Bioética, v. 25, n. 2, 2017.

TEUBER, Gunther. O direito como sistema autopoiético. Lisboa: Calouste Gulbenkian, 1989. 